\title{
Evaluation of dihydrofolate reductase and dihydropteroate synthetase genotypes that confer resistance to sulphadoxine-pyrimethamine in Plasmodium falciparum in Haiti
}

Tamar E Carter ${ }^{1,2,3}$, Megan Warner ${ }^{4,10}$, Connie J Mulligan ${ }^{1,2}$, Alexander Existe ${ }^{5}$, Yves S Victor ${ }^{6}$, Gladys Memnon $^{7}$, Jacques Boncy ${ }^{5}$, Roland Oscar ${ }^{8}$, Mark M Fukuda ${ }^{9}$ and Bernard A Okech ${ }^{4,10^{*}}$

\begin{abstract}
Background: Malaria caused by Plasmodium falciparum infects roughly 30,000 individuals in Haiti each year. Haiti has used chloroquine (CQ) as a first-line treatment for malaria for many years and as a result there are concerns that malaria parasites may develop resistance to CQ over time. Therefore it is important to prepare for alternative malaria treatment options should CQ resistance develop. In many other malaria-endemic regions, antifolates, particularly pyrimethamine (PYR) and sulphadoxine (SDX) treatment combination (SP), have been used as an alternative when CQ resistance has developed. This study evaluated mutations in the dihydrofolate reductase (dhfr) and dihydropteroate synthetase (dhps) genes that confer PYR and SDX resistance, respectively, in $P$. falciparum to provide baseline data in Haiti. This study is the first comprehensive study to examine PYR and SDX resistance genotypes in P. falciparum in Haiti.

Methods: DNA was extracted from dried blood spots and genotyped for PYR and SDX resistance mutations in $P$. falciparum using PCR and DNA sequencing methods. Sixty-one samples were genotyped for PYR resistance in codons 51, 59, 108 and 164 of the dhfr gene and 58 samples were genotyped for SDX resistance codons 436, 437, 540 of the dhps gene in P. falciparum.

Results: Thirty-three percent (20/61) of the samples carried a mutation at codon 108 (S108N) of the dhfr gene. No mutations in dhfr at codons 51,59, 164 were observed in any of the samples. In addition, no mutations were observed in dhps at the three codons $(436,437,540)$ examined. No significant difference was observed between samples collected in urban vs rural sites (Welch's T-test $p$-value $=0.53$ and permutations $p$-value $=0.59$ ).

Conclusion: This study has shown the presence of the S108N mutation in P. falciparum that confers low-level PYR resistance in Haiti. However, the absence of SDX resistance mutations suggests that SP resistance may not be present in Haiti. These results have important implications for ongoing discussions on alternative malaria treatment options in Haiti.
\end{abstract}

Keywords: Malaria, Hispaniola, Folic acid antagonists, Anti-malarials, Drug resistance, Transmission, Fansidar

\footnotetext{
* Correspondence: bokech@ufl.edu

${ }^{4}$ Emerging Pathogens Institute, University of Florida, 2055 Mowry Rd, P.O. Box 100009, Gainesville, FL 32610, USA

${ }^{10}$ Department of Environmental and Global Health, University of Florida,

PO Box 100188, Gainesville, FL 32610, USA

Full list of author information is available at the end of the article
} 


\section{Background}

Malaria causes almost half a million deaths worldwide every year, with Plasmodium falciparum accounting for most of the deaths [1]. In Haiti, roughly 30,000 people contract malaria annually [2], making it a significant public health concern for the country. The treatment for malaria in Haiti has relied on chloroquine (CQ) for several decades [3,4]. However, there is evidence that CQresistance genotypes may be emerging in Haiti $[5,6]$ and there are ongoing discussions about the need to incorporate alternative treatments for the management of malaria.

Many malaria endemic countries that reported CQ resistance switched to antifolate treatments, especially the combination treatment of pyrimethamine (PYR) and sulphadoxine (SDX) [7]. In Haiti, PYR was first introduced in the early 1960s during the global effort to eliminate malaria [3]. The Haiti Ministry of Health, in partnership with the World Health Organization, worked to reduce malaria in Haiti by incorporating PYR in addition to CQ which was already being used [3] and insecticide spraying to kill mosquitoes. After a decade of use, PYR-resistant strains of P. falciparum were reported in Haiti based on in vitro studies [8], but no SP resistance was observed in vivo [8]. Since 1985, there have been no additional comprehensive studies to examine SP resistance in Haiti [9].

The in vitro and in vivo resistance of $P$. falciparum to PYR and SDX has been associated with single point mutations in the dihydrofolate reductase (dhfr) [10-12] and dihydropteroate synthase (dhps) genes [13-15], respectively. These same point mutations have also been associated with SP resistances. Correlations have been found between SP resistance and point mutations at $d h f r$ codons 51, 59, 108, and 164 and dhps codons 436, 437, and 540 [16-20]. The mutation at codon 108 in dhfr is the first to develop in a population under pressure from PYR use [21,22]. The stepwise evolution of additional mutations, particularly at codons 51 and 59, directly correlates with increased resistance to PYR [10,12,23,24]. To date, no comprehensive molecular studies on $d h f r$ and dhps genotypes associated with resistance to PYR and SDX, respectively have been conducted in Haiti beyond a single study that examined only three samples [25].

In this study, genetic markers for SP resistance in the $d h f r$ and dhps genes were assayed in P. falciparum samples from Haiti. The data obtained from this study are important for future anti-malaria drug health policy discussions for Haiti and for understanding the evolution of drug resistance in $P$. falciparum.

\section{Methods}

Study sites

The blood samples were collected from six sites: Terre Noire in Port au Prince at the Blanchard Clinic (TN) and Leogane at the Hospital Sainte Croix (LN), Artibonite (ART), Hinche (HN), Cap Haitien (CP), and Jacmel (JM) (Figure 1). The TN community is very close to Port au Prince international airport and, therefore, is categorized as urban although the public health infrastructure is very poor. $\mathrm{LN}, \mathrm{ART}, \mathrm{HN}, \mathrm{CP}$, and JM are located in rural communities. The rural communities primarily engage in subsistence farming and informal trade for income. There is very limited electricity and piped water. Spring water that feeds into seasonal rivers is a part of the landscape and a source for domestic water that contributes to the growth of malaria-transmitting mosquitoes. There is no active malaria control activity in the area.

\section{Sample collection}

Dried blood spots samples were obtained from 319 individuals. The samples were collected in Haiti between May 2010 and February 2012. Table 1 includes a summary of the sample collection from each site. Two separate inclusion criteria were used for sample collection. The first 196 samples were selected based on presentation of malaria-like symptoms (Sample Set 1) and were collected only from TN. The other 123 samples (Sample Set 2) were included based on positive $P$. falciparum detection using microscopy and included samples from TN $(\mathrm{n}=36), \mathrm{LN}(\mathrm{n}=31)$, ART $(\mathrm{n}=25), \mathrm{HN}(\mathrm{n}=10), \mathrm{CP}$ $(\mathrm{n}=10)$, and JM $(\mathrm{n}=11)$. All malaria-infected patients were treated according to the standard policy available at the clinics. The study was approved by the Haiti Ethical Review Board, UF-IRB, and the Office of Research Protections, US Army Medical Research and Materiel Command (USAMRMC).

\section{DNA extraction}

DNA was extracted from dried blood spots using a methanol wash protocol as previously described [26]. Two $1.2 \mathrm{~mm}$ punches were taken from each dried blood spot sample and placed in $0.2 \mathrm{ml}$ tubes. The punches were soaked in methanol at room temperature for $15 \mathrm{~min}$. The methanol was then removed and the punches air-dried for about $30 \mathrm{~min}$. Sterile DNA grade water (65 ul) was then added to each tube and the tubes were heated to $97^{\circ} \mathrm{C}$ for $15 \mathrm{~min}$.

\section{PCR amplification}

To detect the presence of $P$. falciparum DNA in the samples, the small subunit ribosomal RNA ( $s u$ rRNA) gene of $P$. falciparum was amplified as described in Londono et al. [5]. Subsequent amplification and genotyping of $d h f r$ and dhps was conducted on all Set 1 samples with positive ssu $r R N A$ results and all Set 2 samples. Regions of the dhfr (522 bp) and dhps (438 bp) genes were amplified using a nested PCR protocol as previously described [27] except that the amplicons were 


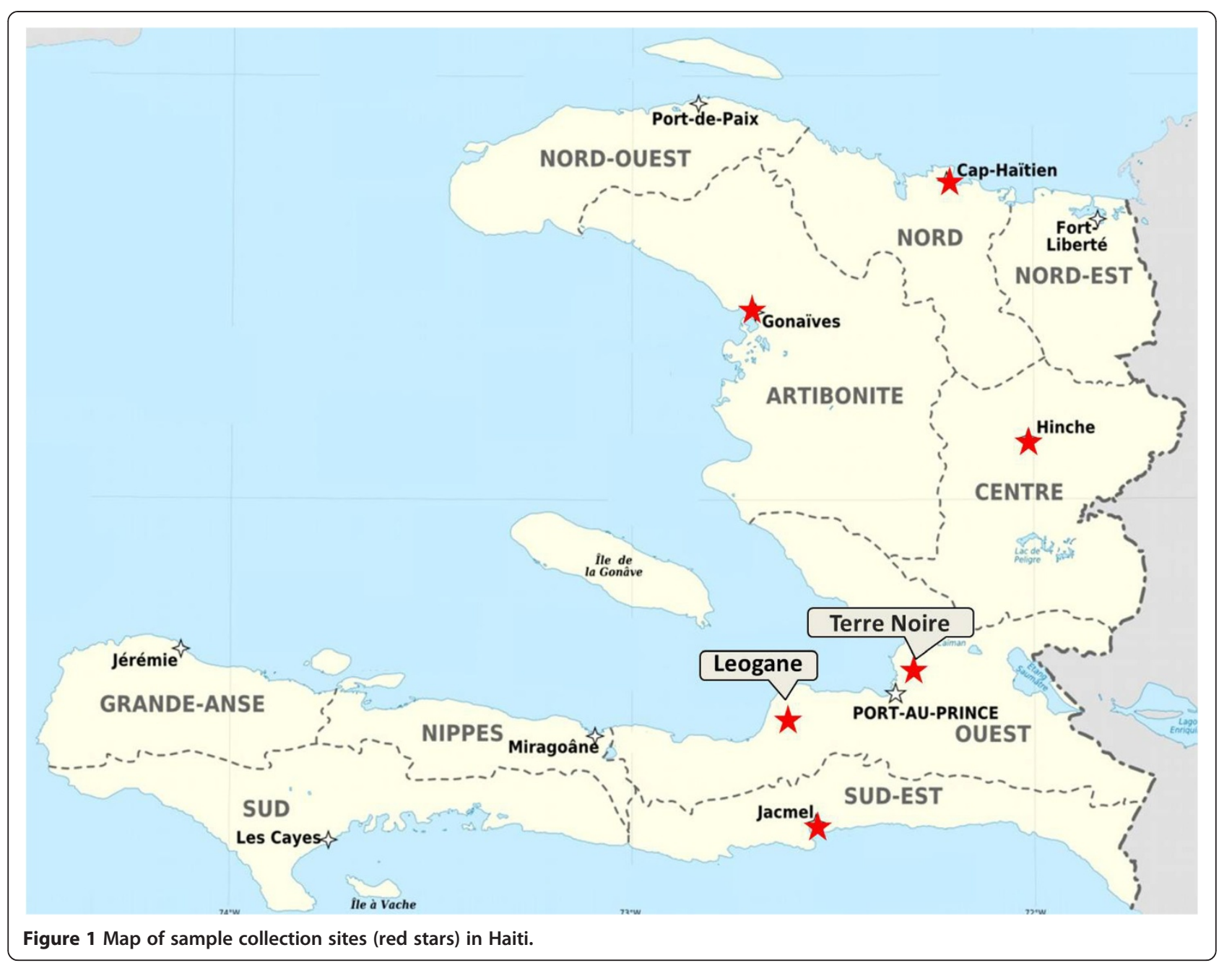

sequenced instead of assayed by restriction digestion. Primer sequences for each nested step and the nucleotide location are listed in Table 2. All PCR reactions included reagents at the following concentrations: $1 \mathrm{X}$ GoTaq Flexi Buffer, $0.75 \mathrm{mM} \mathrm{MgCl}_{2}, 0.2 \mathrm{mM}$ each nucleotide, $0.25 \mu \mathrm{M}$ for each primer, and 1.25 U of Go Taq Hot Start Polymerase (Promega, Madison, WI). The temperature protocol used for all primary PCRs (PCR 1) was as follows: initial denaturation at $94^{\circ} \mathrm{C}$ for $3 \mathrm{~min}, 40$ cycles of denaturation at $94^{\circ} \mathrm{C}$ for $1 \mathrm{~min}$, annealing at $45^{\circ} \mathrm{C}$ for $2 \mathrm{~min}$, extension at $72^{\circ} \mathrm{C}$ for $2 \mathrm{~min}$, and a final extension at $72^{\circ} \mathrm{C}$ for $10 \mathrm{~min}$. The temperature protocol used for the nested PCRs (PCR 2) was as follows: initial denaturation at $94^{\circ} \mathrm{C}$ for $3 \mathrm{~min}, 40$ cycles of denaturation at $94^{\circ} \mathrm{C}$ for $1 \mathrm{~min}$, annealing at $50^{\circ} \mathrm{C}$ for $2 \mathrm{~min}$, extension at $72^{\circ} \mathrm{C}$ for $2 \mathrm{~min}$, and a final extension for $10 \mathrm{~min}$.

Table 1 Sampling summary

\begin{tabular}{llccc}
\hline Study Site & Classification & No. of samples tested & $\begin{array}{l}\text { No. presumptively diagnosed } \\
\text { based on symptoms }\end{array}$ & $\begin{array}{c}\text { No. confirmed } \\
\text { by microscopy }\end{array}$ \\
\hline Terre Noire & Urban & 232 & 196 & 36 \\
Leogane & Rural & 31 & 0 & 31 \\
Artibonite & Rural & 25 & 0 & 25 \\
Hinche & Rural & 10 & 0 & 10 \\
Cap Haitien & Rural & 10 & 0 & 10 \\
Jacmel & Rural & 11 & 0 & 11 \\
Total & - & 319 & 0 & 123 \\
\hline
\end{tabular}


Table 2 Primer sequences used for nested PCR protocol and sequencing

\begin{tabular}{|c|c|c|c|c|}
\hline Gene & Primer & Sequence & Nucleotide location & \\
\hline \multirow[t]{4}{*}{$\overline{d h f r}$} & PCR1 & $M 1^{*}$ & TITATGATGGAACAAGTCTGC & -3 to 18 \\
\hline & & $M 5^{*}$ & AGTATATACATCGCTAACAGA & 625 to 645 \\
\hline & PCR2 & $M 3^{*}$ & TITATGATGGAACAAGTCTGCGACGTT & -3 to 24 \\
\hline & & $\mathrm{F} /{ }^{*}$ & AAATTCTTGATAAACAACGGAACCTTTIA & 491 to 519 \\
\hline \multirow[t]{5}{*}{ dhps } & PCR1 & $\mathrm{R} 2^{*}$ & AACCTAAACGTGCTGTTCAA & 223 to 242 \\
\hline & & $\mathrm{R} / *$ & AATTGTGTGATTTGTCCACAA & 913 to 933 \\
\hline & PCR2 & $K^{*}$ & TGCTAGTGTTATAGATATAGGATGAGCATC & 269 to 298 \\
\hline & & $\mathrm{K}^{*}$ & CTATAACGAGGTATTGCATTTAATGCAAGAA & 676 to 706 \\
\hline & Seq & $\mathrm{Kb}^{+}$ & ATTGGTTCGCATCACATTT & 408 to 427 \\
\hline
\end{tabular}

†Primer sequences listed as forward primer first followed by reverse primer. All primers listed $5^{\prime}$ to $3^{\prime}$.

*Primers taken from Duraisingh et al. [27].

tPrimer designed for nested sequencing of dhps codon 436 and 437.

\section{Sequencing and alignment}

PCR products were Sanger sequenced at the University of Florida's Interdisciplinary Center for Biotechnology Research DNA Sequencing Core Laboratory with BigDye ${ }^{\mathrm{TM}}$ chemistry (Applied Biosystems, Foster City, CA) on an Applied Biosystems 3730 Genetic Analyzer. The PCR 2 forward and reverse primers were used for sequencing the dhfr and dhps PCR amplicons. An additional primer ( $\mathrm{Kb}$, see Table 2 for primer sequence) was designed for nested sequencing of dhps amplicons that gave poor sequences with the PCR 2 primers for the region including codons 436 and 437. Sequence data were aligned to P. falciparum 3D7 sequences [GenBank: XM_001351443 and XM_001349382] using Sequencher 4.10.1. (Gene Codes Corp). The dhfr and dhps gene sequences were scanned for previously identified $d h f r$ and $d h p s$ point mutations in resistance-associated codons (see Table 3).

\section{Statistical analysis}

Welch's t-test and permutations were used to determine if there was a significant difference in the number of samples with detectable levels of $P$. falciparum DNA (ie, positive PCR results with ssu rRNA, dfhr, or dhps) between Sample Set 1 and Sample Set 2. Additionally, the proportion of samples that carried each resistance-

Table 3 List of wild type and resistance codon sequences

\begin{tabular}{lcll}
\hline Gene & Codon & $\begin{array}{l}\text { Wild type codon(s) } \\
\text { (amino acid) }\end{array}$ & $\begin{array}{l}\text { Resistance codon(s) } \\
\text { (amino acid) }\end{array}$ \\
\hline dhfr & 51 & AAT, AAC (N) & ATT (I) \\
& 59 & TGT (C) & CGT (R) \\
& 108 & AGC (S) & AAC (N), ACC (T) \\
& 164 & ATA (I) & TTA (L) \\
dhps & 436 & TCT (S) & GCT (A), TTT (F) \\
& 437 & GCT (A) & GGT (G) \\
& 540 & AAA (K) & GAA (E) \\
\hline
\end{tabular}

associated mutation was determined. Welch's t-test and permutations were used to compare the proportion of samples with mutations between samples collected in an urban region (TN) to samples collected in a rural region ( $\mathrm{LN}, \mathrm{CP}, \mathrm{HN}$, and $\mathrm{JM})$. All statistical analysis were completed using the open source software package $\mathrm{R}$ version 2.14.1 [28].

\section{Results}

Sampling summary and positive amplification results A total of 319 samples were collected in this study. Sample Set 1 included 196 samples and Sample Set 2 included 123 samples (see Table 1). A summary of amplification results for the three genes is presented in Table 4. The proportion of samples with detectable levels of $P$. falciparum DNA (i e, positive amplification of ssu rRNA, dhfr, or dhps) was compared between Sample Set 1 and Sample Set 2 for the TN site. The proportions (Sample Set $1=0.07$ and Sample Set $2=0.72$ ) were determined to be significantly different as assessed by Welch's T-test and permutation ( $\mathrm{p}$-value $<<0.001$ ).

The dhfr and dhps genes were amplified in Set 1 samples with positive $s s u$ rRNA results and Set 2 samples. Of these samples, 65 were successfully PCR amplified for the dhfr gene and 61 samples were successfully sequenced [Genbank: JX217825 - JX217828]. Likewise, the dhps gene was successfully amplified in 73 samples and 58 samples were successfully sequenced. Finally, complete and matched dhfr and dhps sequence data were available for 46 samples.

\section{Dhfr and dhps mutations}

Of the 61 samples that were successfully sequenced for dhfr, 20 samples (32.79\%) carried the S108N mutation (Table 5) [Genbank: JX217825]. Wild type alleles were observed in all samples at dhfr codons 51, 59, and 164 (Table 5). Other studies have reported two possible wild 
Table 4 Amplification and sequencing results

\begin{tabular}{|c|c|c|c|c|c|c|c|}
\hline \multirow[t]{2}{*}{ Study Site } & \multirow{2}{*}{$\begin{array}{l}\text { Total } \\
\text { samples }\end{array}$} & \multicolumn{3}{|c|}{ \# Positive amplifications } & \multicolumn{3}{|l|}{ \# Sequenced } \\
\hline & & ssu rRNA & $d h f r$ & dhps & $d h f r$ & dhps & Both dhfr and dhps \\
\hline Terre Noire † & 232 & $\begin{array}{l}39(\mathrm{SS} 1=13 \\
\mathrm{SS} 2=26)\end{array}$ & $\begin{array}{l}33(\mathrm{SS} 1=12 \\
\mathrm{SS} 2=21)\end{array}$ & $\begin{array}{l}31(S S 1=10 \\
S S 2=21)\end{array}$ & $\begin{array}{l}30(\mathrm{SS} 1=12 \\
\mathrm{SS} 2=18)\end{array}$ & $\begin{array}{l}23(\mathrm{SS} 1=10 \\
\mathrm{SS} 2=13)\end{array}$ & $\begin{array}{l}21(S S 1=10 \\
S S 2=11)\end{array}$ \\
\hline Leogane & 31 & 24 & 14 & 18 & 13 & 13 & 10 \\
\hline Hinche & 10 & 6 & 5 & 8 & 5 & 8 & 4 \\
\hline Cap Haitien & 10 & 1 & 4 & 8 & 4 & 7 & 4 \\
\hline Jacmel & 11 & 6 & 9 & 8 & 9 & 7 & 7 \\
\hline Total* & 294 & 76 & 65 & 73 & 61 & 58 & 46 \\
\hline
\end{tabular}

tIncludes the number of samples for samples set (SS) in parentheses; SS1 = Sample Set 1 and SS2 = Sample Set 2.

*Total does not include Artibonite samples. None of the Artibonite samples contained positive amplifications for ssu rRNA, dhfr, or $d h p s$.

type alleles for the dhfr codon 51, AAT and AAC, both coding for asparagine, (N) (Table 3), but only the AAT allele was observed in this study's samples. In addition to the S108N mutation, a mutation was observed in codon 62 in a single sample that resulted in an amino acid change from threonine, ( $\mathrm{T}$ ) to leucine, (L) [Genbank: JX217827]. Another mutation was observed in codon 158 of two samples that resulted in an amino change from aspartic acid to glycine [Genbank: JX217825]. No mutations were observed in the dhps gene in the samples.

\section{Urban and rural S108N frequency comparison}

Of the 61 samples that were successfully sequenced for $d h f r, 30$ samples were collected from an urban site (TN) and 31 were collected from rural sites (LN, HN, CP, and JM). The proportion of samples with the S108N mutation in each study site is represented in Figure 2. Eleven (36.67\%) of the samples collected from the urban site and nine $(29.03 \%)$ from the rural sites had the S108N mutation. The proportion of samples with the S108N mutation did not differ significantly between the samples collected in urban $v s$ rural sites, based on Welch's T-test ( $p$-value $=0.53)$ and permutations $(p$-value $=0.59)$, suggesting that that samples collected from the urban site are not significantly more likely to carry the S108N mutation than the samples from the rural site.

Table 5 Percent of samples with S108N mutation for each collection site

\begin{tabular}{lll}
\hline Study Site & \# DHFR sequenced & S108N mutants (\%) \\
\hline Terre Noire & 30 & $11(36.67 \%)$ \\
Leogane & 13 & $2(13.33 \%)$ \\
Hinche & 5 & $0(0 \%)$ \\
Cap Haitien & 4 & $1(25 \%)$ \\
Jacmel & 9 & $6(66.67 \%)$ \\
Total & 61 & $20(32.79 \%)$ \\
\hline
\end{tabular}

\section{Discussion}

\section{Sampling summary and presence of Plasmodium falciparum DNA}

The purpose of the present study was to investigate the presence of SP resistance associated mutations in the dhfr and dhps genes in P. falciparum in Haiti. As reported in Table 1, a total of 319 samples were collected. However, only 76 samples, or $24 \%$, had positive ssu rRNA amplification. An additional 16 samples from Set 2 amplified dhfr or dhps, although they did not successfully amplify ssu rRNA. Furthermore, there was a significant disparity in the number of samples with detectable levels of P. falciparum DNA (i e, positive amplification for ssu rRNA, dhfr, or dhps) between the samples that were collected based on malaria-like symptoms (Sample Set 1) and microscopy (Sample Set 2) from $\mathrm{TN}$ ( $\mathrm{p}$-value $<<0.001$ ). It is likely that malaria is often over-diagnosed in Haiti as the symptoms of malaria (fever, chills, fatigue, etc.) are similar to that of other diseases, thus the samples from Set 1 were less likely to contain P. falciparum DNA.

\section{PYR-resistance mutations}

Sixty-one samples were sequenced successfully for $d h f r$ and 20 of these samples carried the S108N dhfr mutation associated with PYR resistance. No other resistance mutations genotyped in the $d h f r$ gene were observed. Previous studies have reported that the S108N mutation is essential to PYR resistance $[10,11,29]$ and is the first mutation seen as PYR resistance develops [21,22]. The single S108N mutation is associated with a lower level of resistance to PYR relative to multi-allelic resistance associated with S108N plus other mutations at codon positions 51, 59, and $164[10,12,23,24]$. Therefore, these results suggest that there may be PYR resistance in Haiti and that the resistance would be low based on the absence of multiple mutations at codons 51, 59, and 164 in the $P$. falciparum samples analysed.

Continued presence of PYR-resistant S108N-only haplotypes in Haiti decades after PYR use was 


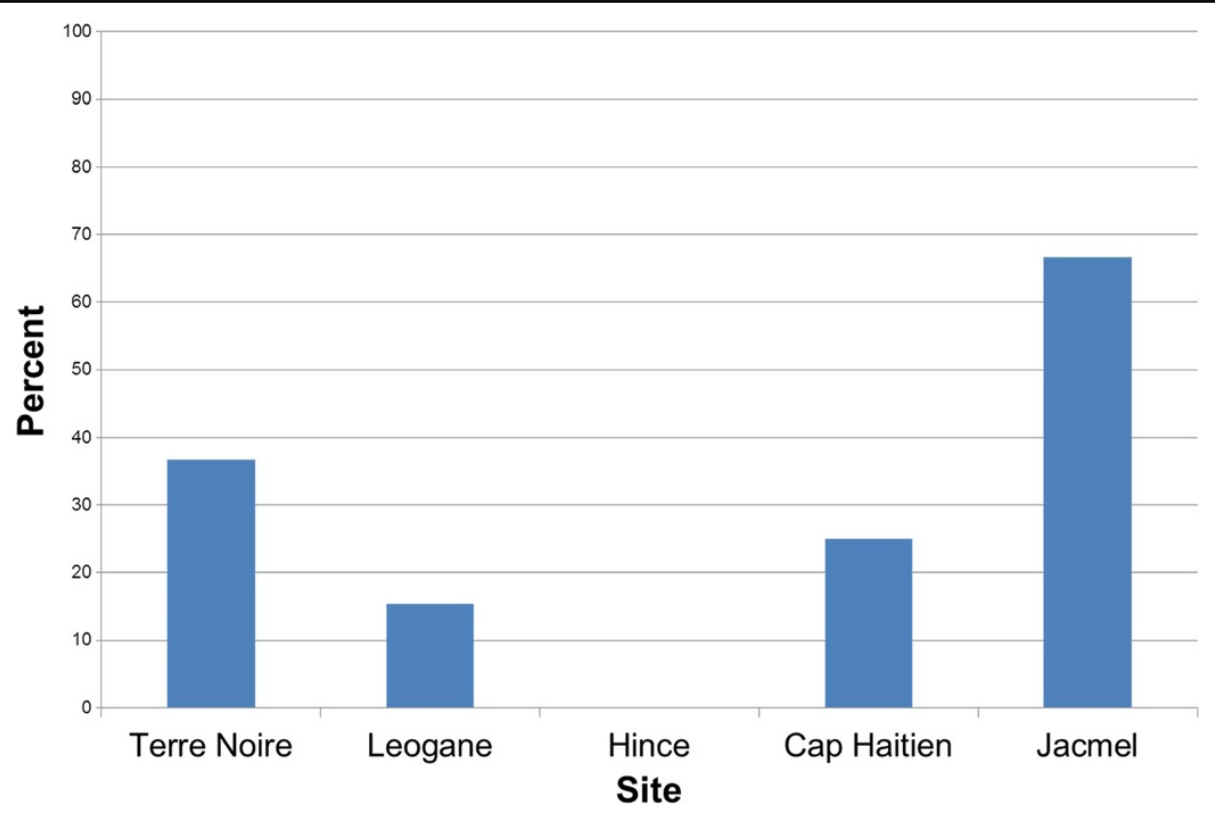

Figure 2 Comparison of the prevalence of S108N mutation by collection site.

discontinued seems surprising. In this study, only the single S108N haplotype was observed, while in other studies the S108N mutation is rarely observed alone. Recent studies of discontinued use of SP in Peru, followed up to five years, have noted a decrease in multiple mutation dhfr haplotypes while noting an increase in $\mathrm{S} 108 \mathrm{~N}$ only haplotypes [30,31]. This may be due to a greater fitness cost for multiple mutation haplotypes in the absence of antifolate drug pressure [31]. However, no studies have documented a complete loss of S108N haplotypes following discontinued use of SP; thus, it is not possible to calculate how quickly S108N may be lost. Furthermore, studies have not found evidence of strong selective pressure on the S108N-only haplotype [32] suggesting that there may be minimal fitness costs associated with maintaining only the S108N allele. Another possible explanation for the presence of a PYR-resistant mutation in Haiti is that privately run clinics funded by charities and unregulated donations of medications may be using SP regimes for the clinical management of malaria in Haiti. There is no evidence that this is happening but the lack of government oversight of private clinics run by charities may lead to unauthorized medications being used. There is also the possibility of crossresistance due to sulphonamide-based treatments for HIV that act on the folate pathway and may induce mutations in P. falciparum dhfr gene [33]. Iyer et al. found that $P$. falciparum strains with the S108N mutation were resistant to the sulphadmide-based HIV treatment trimethoprim [33], suggesting that widespread use of trimethoprim could result in selection of resistance mutations in the dhfr. Another possibility is that the S108N mutation may have been introduced from South American countries, such as Bolivia, Columbia, or Peru where PYR or SP has been used or is being used. For example, a study in Peru reported a $79 \%$ prevalence of the single S108N haplotype [31]. Corredor et al. also reported an increase in the single S108N haplotypes to $26 \%$ in the Amazon basin in Colombia [34]. Few studies have examined the presence of $d h f r$ resistance haplotypes in Central America, with the exception of Jovel et al. [35] (Honduras) and Samudio et al. [36] (Panama). Neither of these studies observed the single S108N haplotype in their samples. Investigations into the origin of the $d h f r \mathrm{~S} 108 \mathrm{~N}$ mutation in Haiti could provide insight into how drug resistance mutations arise and spread throughout a population.

Two additional mutations in the $d h f r$ (T62L and D148G) that have not previously been reported were observed in this study. Both mutations result in a change in side-chain polarity of the amino acid (polar to nonpolar) and the D148G mutation results in a change of side-chain charge, suggesting that these mutations may affect $P$. falciparum functionality. Further studies are needed to investigate whether these mutations affect resistance to PYR.

\section{SDX resistance mutations}

The lack of mutations in the dhps genes in the samples suggests that no drug pressure has been acting upon the gene. Further studies are recommended to increase the sample size and sampling sites and to conduct in vitro 
sensitivity studies on SDX in malaria parasites from Haiti. Nonetheless, based on the data in this paper, the lack of mutations in the dhps may indicate that $P$. falciparum parasites in Haiti are still sensitive to SDX.

\section{Conclusion}

The finding of the $d h f r$ S108N mutation would suggest that PYR-resistant $P$. falciparum may still be present in Haiti, at least at a low level. However, S108N alone has not been associated with SP resistance and, thus, the use of combination SP for the treatment of malaria in Haiti should be considered as a replacement medication in the event that CQ resistance emerges.

\section{Competing interests}

The authors declare that they have no competing interests.

\section{Authors' contributions}

TEC contributed to the design of the study, completed molecular genetic studies, statistical analysis and interpretation, and drafted the manuscript. MW generated a portion of the molecular data. CJM contributed to the study design, interpretation of results, and the writing of the manuscript. AE organized collection of samples in Haiti and interpretation of data. JSV, GM, $\mathrm{JB}$ and $\mathrm{RO}$ collected samples in Haiti. MF assisted with the drafting of the manuscript. BAO designed the study, facilitated sample collection in Haiti, and contributed interpretation of the data and the drafting of manuscript All authors read and approved the final manuscript.

\section{Acknowledgements}

The authors would like to thank the following organizations for their support: Ministry of Sanitation and Public Practice (MSPP), Government of Haiti, Christianville Foundation, Gressier Haiti, Fish Ministries Haiti, Family Health Ministries, University of Florida, and US Department of Defense. This material is based upon work supported by the Department of Defense Global Emerging Infections Surveillance \& Response System (DoD-GEIS) Grant No. C0607_12_UN awarded to BAO and the National Science Foundation Graduate Research Fellowship under Grant No. DGE-0802270 awarded to TEC.

\section{Author details}

${ }^{1}$ Genetics Institute, University of Florida, 2033 Mowry Road, PO Box 103610, Gainesville, FL 32610, USA. ²Department of Anthropology, University of Florida, Turlington Hall, Room 1112, PO Box 117305, Gainesville, FL 32611, USA. ${ }^{3}$ Department of Epidemiology, College of Public Health and Health Professions, University of Florida, 1225 Center Drive, Room 3101, PO Box 100231, Gainesville, FL 32611, USA. ${ }^{4}$ Emerging Pathogens Institute, University of Florida, 2055 Mowry Rd, P.O. Box 100009, Gainesville, FL 32610, USA. ${ }^{5}$ National Public Health Laboratory, Ministry of Public Health and Population (MSPP), Port au Prince, Haiti. ${ }^{6}$ Blanchard Clinic, Family Health Ministries Haiti, Terre Noire, Port au Prince, Haiti. ${ }^{7}$ Hospital Saint Croix, Leogane, Haiti. ${ }^{8}$ National Malaria Control Program, Ministry of Public Health and Population, Port au Prince, Haiti. ${ }^{9}$ Armed Forces Health Sciences Surveillance Center, 11800 Tech Road, Suite 220, Silver Spring, MD 20904, USA. ${ }^{10}$ Department of Environmental and Global Health, University of Florida, PO Box 100188, Gainesville, FL 32610, USA

Received: 28 June 2012 Accepted: 1 August 2012

Published: 13 August 2012

\section{References}

1. WHO: World Malaria Report 2011. Geneva: World Health Organization; 2011

2. WHO: World Malaria Report 2010. Geneva: World Health Organization; 2010.

3. World Health Organization: Malaria Eradication in 1965. WHO Chron 1966, 20:286-300.

4. Meeting of the International Task Force for Disease Eradication--12 May 2006: Wkly Epidemiol Rec 2007, 82:25-30.
5. Londono BL, Eisele TP, Keating J, Bennet A, Chattopadhyay C, Heyliger G, Mack B, Rawson I, Vely J-F, Desinor O, Krogstad DJ: Chloroquine-resistant haplotype Plasmodium falciparum parasites, Haiti. Emerg Infect Dis 2009, 15:735-740.

6. Londono-Renteria B, Eisele TP, Keating J, Bennett A, Krogstad DJ: Genetic diversity in the merozoite surface protein 1 and 2 genes of Plasmodium falciparum from the Artibonite Valley of Haiti. Acta Trop 2012, 121:6-12.

7. Sridaran S, McClintock SK, Syphard LM, Herman KM, Barnwell JW, Udhayakumar V: Anti-folate drug resistance in Africa: Meta-analysis of reported dihydrofolate reductase (dhfr) and dihydropteroate synthase (dhps) mutant genotype frequencies in African Plasmodium falciparum parasite populations. Malar J 2010, 9:247.

8. Nguyen-Dinh P, Zevallos-Ipenza A, Magloire R: Plasmodium falciparum in Haiti: Susceptibility to pyrimethamine and sulfadoxine-pyrimethamine. Bull World Health Organ 1984, 62:623-626.

9. Nguyen-Dinh P, Payne D, Teklehaimanot A, Zevallos-Ipenza A, Day MM, Duverseau YT: Development of an in vitro microtest for determining the susceptibility of Plasmodium falciparum to sulfadoxine-pyrimethamine: Laboratory investigations and field studies in Port-au-Prince, Haiti. Bull World Health Organ 1985, 63:585-592.

10. Cowman AF, Morry MJ, Biggs BA, Cross GA, Foote SJ: Amino acid changes linked to pyrimethamine resistance in the dihydrofolate reductasethymidylate synthase gene of Plasmodium falciparum. Proc Natl Acad Sci USA 1988, 85:9109-9113.

11. Peterson DS, Walliker D, Wellems TE: Evidence that a point mutation in dihydrofolate reductase-thymidylate synthase confers resistance to pyrimethamine in falciparum malaria. Proc Natl Acad Sci USA 1988, 85:9114-9118.

12. Basco LK, de Eldin Pecoulas P, Wilson CM, Le Bras J, Mazabraud A: Point mutations in the dihydrofolate reductase-thymidylate synthase gene and pyrimethamine and cycloguanil resistance in Plasmodium falciparum. Mol Biochem Parasitol 1995, 69:135-138.

13. Brooks DR, Wang P, Read M, Watkins WM, Sims PF, Hyde JE: Sequence variation of the hydroxymethyldihydropterin pyrophosphokinase: dihydropteroate synthase gene in lines of the human malaria parasite, Plasmodium falciparum, with differing resistance to sulfadoxine. Eur J Biochem 1994, 224:397-405.

14. Wang P, Read M, Sims PF, Hyde JE: Sulfadoxine resistance in the human malaria parasite Plasmodium falciparum is determined by mutations in dihydropteroate synthetase and an additional factor associated with folate utilization. Mol Microbiol 1997, 23:979-986.

15. Triglia T, Wang P, Sims PF, Hyde JE, Cowman AF: Allelic exchange at the endogenous genomic locus in Plasmodium falciparum proves the role of dihydropteroate synthase in sulfadoxine-resistant malaria. EMBO J 1998, 17:3807-3815

16. Kublin JG, Dzinjalamala FK, Kamwendo DD, Malkin EM, Cortese JF, Martino LM, Mukadam RG, Rogerson SJ, Lescano AG, Molyneux ME, Winstanley PA, Chimpeni P, Taylor TE, Plowe CV: Molecular markers for failure of sulfadoxine-pyrimethamine and chlorproguanil-dapsone treatment of Plasmodium falciparum malaria. J Infect Dis 2002, 185:380-388.

17. Nzila AM, Mberu EK, Sulo J, Dayo H, Winstanley PA, Sibley $\mathrm{CH}$, Watkins WM: Towards an understanding of the mechanism of pyrimethaminesulfadoxine resistance in Plasmodium falciparum : Genotyping of dihydrofolate reductase and dihydropteroate synthase of Kenyan parasites. Antimicrob Agents Chemother 2000, 44:164-169.

18. Plowe CV, Cortese JF, Djimde A, Nwanyanwu OC, Watkins WM, Winstanley P, Estrada-Franco JG, Mollinedo RE, Avila JC, Cespedes JL, Carter D, Doumbo OK: Mutations in Plasmodium falciparum dihydrofolate reductase and dihydropteroate synthase and epidemiologic patterns of pyrimethamine-sulfadoxine use and resistance. J Infect Dis 1997 176:1590-1596.

19. Jelinek T, Ronn AM, Lemnge MM, Curtis J, Mhina J, Duraisingh MT Bygbjerg IC, Warhurst DC: Polymorphisms in the dihydrofolate reductase (DHFR) and dihydropteroate synthetase (DHPS) genes of Plasmodium falciparum and in vivo resistance to sulphadoxine/ pyrimethamine in isolates from Tanzania. Trop Med Int Health 1998, 3:605-609

20. Jelinek T, Kilian AH, Kabagambe G, von Sonnenburg F: Plasmodium falciparum resistance to sulfadoxine/pyrimethamine in Uganda: Correlation with polymorphisms in the dihydrofolate reductase and dihydropteroate synthetase genes. Am J Trop Med Hyg 1999, 61:463-466. 
21. Sirawaraporn W, Sathitkul T, Sirawaraporn R, Yuthavong Y, Santi DV: Antifolate-resistant mutants of Plasmodium falciparum dihydrofolate reductase. Proc Natl Acad Sci USA 1997, 94:1124-1129.

22. Lozovsky ER, Chookajorn T, Brown KM, Imwong M, Shaw PJ, Kamchonwongpaisan S, Neafsey DE, Weinreich DM, Hartl DL: Stepwise acquisition of pyrimethamine resistance in the malaria parasite. Proc Natl Acad Sci USA 2009, 106:12025-12030.

23. Nzila-Mounda A, Mberu EK, Sibley CH, Plowe CV, Winstanley PA, Watkins WM: Kenyan Plasmodium falciparum field isolates: Correlation between pyrimethamine and chlorcycloguanil activity in vitro and point mutations in the dihydrofolate reductase domain. Antimicrob Agents Chemother 1998, 42:164-169.

24. Peterson DS, Milhous WK, Wellems TE: Molecular basis of differential resistance to cycloguanil and pyrimethamine in Plasmodium falciparum malaria. Proc Natl Acad Sci USA 1990, 87:3018-3022.

25. Cortese JF, Caraballo A, Contreras CE, Plowe CV: Origin and dissemination of Plasmodium falciparum drug-resistance mutations in South America. $J$ Infect Dis 2002, 186:999-1006.

26. Bereczky S, Mårtensson A, Gil JP, Färnert A: Rapid DNA extraction from archive blood spots on filter paper for genotyping of Plasmodium falciparum. Am J Trop Med Hyg 2005, 72:249-251.

27. Duraisingh MT, Curtis J, Warhurst DC: Plasmodium falciparum: Detection of polymorphisms in the dihydrofolate reductase and dihydropteroate synthetase genes by PCR and restriction digestion. Exp Parasitol 1998, 89:1-8.

28. R Development Core Team: A Language and Environment for Statistical Computing. 2141st edition. Vienna, Austria: R Foundation for Statistical Computing; 2011.

29. Reeder JC, Rieckmann KH, Genton B, Lorry K, Wines B, Cowman AF: Point mutations in the dihydrofolate reductase and dihydropteroate synthetase genes and in vitro susceptibility to pyrimethamine and cycloguanil of Plasmodium falciparum isolates from Papua New Guinea. Am J Trop Med Hyg 1996, 55:209-213.

30. Zhou Z, Griffing SM, de Oliveira AM, McCollum AM, Quezada WM, Arrospide $\mathrm{N}$, Escalante AA, Udhayakumar V: Decline in sulfadoxine-pyrimethamineresistant alleles after change in drug policy in the Amazon region of Peru. Antimicrob Agents Chemother 2008, 52:739-741.

31. Bacon DJ, McCollum AM, Griffing SM, Salas C, Soberon V, Santolalla M, Haley R, Tsukayama P, Lucas C, Escalante AA, Udhayakumar V: Dynamics of malaria drug resistance patterns in the Amazon basin region following changes in Peruvian national treatment policy for uncomplicated malaria. Antimicrob Agents Chemother 2009, 53:2042-2051.

32. Roper C, Pearce R, Bredenkamp B, Gumede J, Drakeley C, Mosha F Chandramohan D, Sharp B: Antifolate antimalarial resistance in southeast Africa: A Population-based analysis. Lancet 2003, 361:1174-1181.

33. Iyer JK, Milhous WK, Cortese JF, Kublin JG, Plowe CV: Plasmodium falciparum cross-resistance between trimethoprim and pyrimethamine. Lancet 2001, 358:1066-1067.

34. Corredor V, Murillo C, Echeverry DF, Benavides J, Pearce RJ, Roper C, Guerra AP, Osorio L: Origin and dissemination across the Colombian Andes mountain range of sulfadoxine-pyrimethamine resistance in Plasmodium falciparum. Antimicrob Agents Chemother 2010 54:3121-3125.

35. Jovel IT, Mejia RE, Banegas E, Piedade R, Alger J, Fontecha G, Ferreira PE, Veiga MI, Enamorado IG, Bjorkman A, Ursing J: Drug resistance associated genetic polymorphisms in Plasmodium falciparum and Plasmodium vivax collected in Honduras. Central America. Malar J 2011, 10:376.

36. Samudio F, Santamaria AM, Obaldia N 3rd, Pascale JM, Bayard V, Calzada JE: Prevalence of Plasmodium falciparum mutations associated with antimalarial drug resistance during an epidemic in Kuna Yala, Panama, Central America. Am J Trop Med Hyg 2005, 73:839-841.

\section{doi:10.1186/1475-2875-11-275}

Cite this article as: Carter et al:: Evaluation of dihydrofolate reductase and dihydropteroate synthetase genotypes that confer resistance to sulphadoxine-pyrimethamine in Plasmodium falciparum in Haiti. Malaria Journal 2012 11:275.

\section{Submit your next manuscript to BioMed Central and take full advantage of:}

- Convenient online submission

- Thorough peer review

- No space constraints or color figure charges

- Immediate publication on acceptance

- Inclusion in PubMed, CAS, Scopus and Google Scholar

- Research which is freely available for redistribution 